\title{
The Design of Wheel Fanpa Machine
}

\author{
Jinling Zhao and Mei Tian \\ College of Mechanical Engineering, Jilin Engineering Normal University, No. 3050 Kaixuan Road \\ Kuancheng District, 130052 Changchun China \\ 522927259@qq.com, 32593829@qq.com
}

Keywords: Wheel repair; Back wheel; Equipment; Creative design

\begin{abstract}
This paper mainly introduces the design process of a new type of non - standard equipment which is suitable for the maintenance of many kinds of locomotive wheel sets. The working principle, working process and structure characteristics are discussed in this paper. The design and calculation of the main technical parameters are carried out.
\end{abstract}

\section{Preface}

In the process of Wheelsets of locomotives and vehicles maintenance, first of all to the wheel on the axle back, axle, gear and other components maintenance on the new tires to pressure mounted on the axle, and according to the provisions of the wheelset of back pressure test. In China's railway vehicle repair factory for repair of the locomotive wheel has a variety of, such as: Dongfeng 4D locomotive wheelset, dongfeng 4dk locomotive semi suspension wheelset, dongfeng 4dk locomotive full suspension wheel and so on, the factory original wheels' repair using the back wheel device are axle press fit machine.[1] Due to the axle press fit the inherent structure of the machine, if we want to realize wheel on the axle back this process, it must be equipped with special heavy and large tooling, the back wheel method is not only low work efficiency, and wheel and axle strain phenomenon frequently. With the speeding up of railway vehicle running, trunk on the use of locomotive is gradually replaced by electric locomotive, electric locomotive wheelset structure complex, two sets of gear drive, the smaller distance between the wheel and gear. If still using the original cannot achieve wheel apparatus and method for annealing. Therefore, the design of a suitable for a variety of Wheelsets of locomotives and cars back wheel special equipment is very necessary.

\section{Main Technical Specifications}

According to the design drawings and technical documents for the factory maintenance experience and a variety of locomotive and vehicle wheel wheel, determine the maximum pressure of the main oil cylinder turbine wheel and should reach 300 tons. The highest tonnage mobile car cylinder should reach 5 tons.[2]

Main oil cylinder part:

Working pressure: 266t ; Rated pressure: $31.5 \mathrm{MPa}$ Cylinder diameter: $\phi 400 \mathrm{~mm}$;

Working stroke: $450 \mathrm{~mm}$ Piston working speed: $v \leq 1.54 \mathrm{~mm} / \mathrm{s}$

The parts of Mobile car:

Rated load: $\mathrm{G}=5 \mathrm{t}$; Rated pressure: $6.3 \mathrm{MPa}$ Cylinder diameter: $\phi 140 \mathrm{~mm}$

Working stroke: $160 \mathrm{~mm}$ Horizontal rotation angle: $360^{\circ}$

\section{Working Process}

Basic working process (see Fig. 1): 1) Check wheel set 7 on wheel axle bearing 8(Different types of wheel sets with different support);2) Start jack up cylinder 10, Adjusting the protruding height of the piston rod to make the main oil cylinder 4 and the center line of the wheel pair;3) Three tie rod 5 on the main oil cylinder is connected with the wheel pair and fixed;4) Start a high-pressure oil pump and to the inside of the wheel set oil hole injection high pressure oil and until the wheel and 
the shaft is matched with the surface of a high pressure oil exudation, maintaining the pressure;5) Starting the main oil cylinder, the piston rod is extended to separate the wheel from the shaft;[3]6) Close the high pressure oil pump and the main oil cylinder.7) The wheel axle bearing on the rotary trolley will be turned around, and the other side of the wheel can be removed.

In a back pressure test wheel and preset the tonnage of back pressure, when the pressure reaches back pressure value, the main cylinder stop working automatically, pressure, displacement recorder timely record displacement, pressure curves and output, reflect the results of equipment maintenance. That is, the pressure test is not required to use high pressure lubricator.

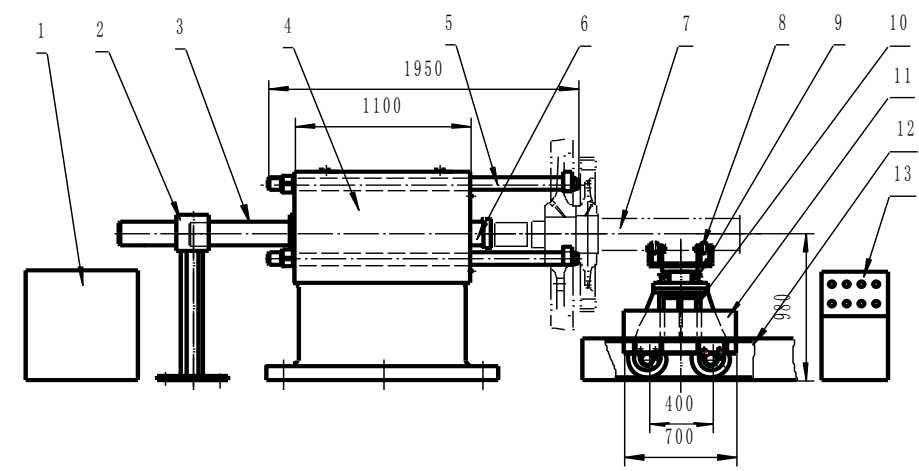

1 hydraulic station 2 guide support 3 guide rod 4 main oil cylinder 5 rod 6 piston rod 7 is detected wheel 8 wheel set bearing 9 thrust bearing 10 jack cylinder 11 mobile trolley 12 trolley guide rail 13 electric control operating table

Figure 1. Schematic diagram of the basic working process of the wheel set

Use the tool working process (see Fig. 2): 1 cylinder body of rod position is fixed, so it only with a model of wheelset fit,[4] in order to meet the needs of a variety of wheelset repair, equipped with a series of industry and trade, use the tooling after working process can be summarized as follows: 1) pull rod 1 and connecting plate 3 nut with a round 2 and the clip block 4 assembly; (2) the connecting plate 3 through a pull rod 5, a clamping block 6 and the wheel is connected; 3 ) repeat the basic working process.

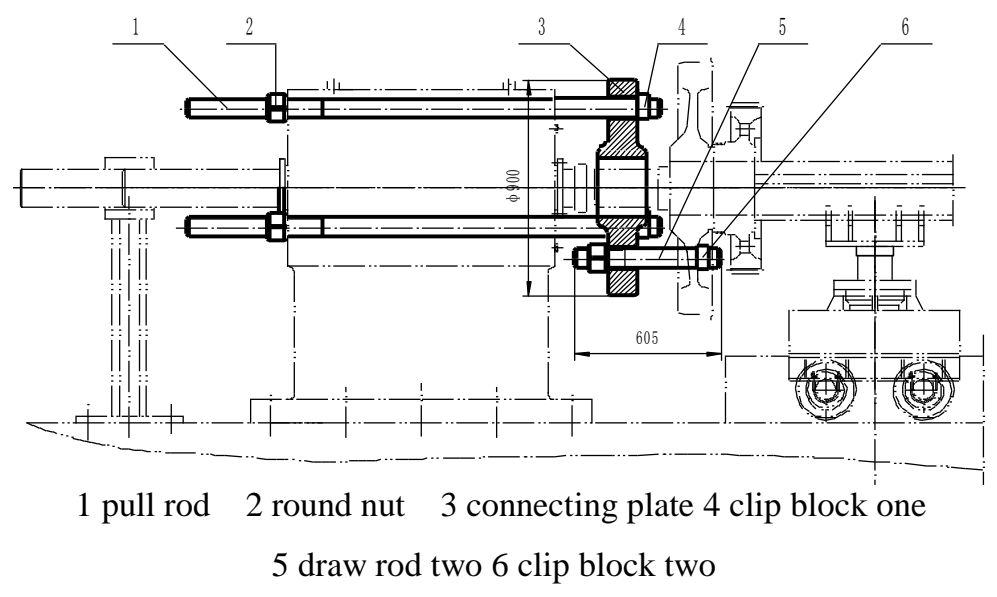

Figure 2. Schematic diagram of the assembly and assembly of the wheel set

\section{Structure Characteristics}

Fanpa Machine. Mainly by the main oil cylinder, a moving car, tooling ( 3 sets), hydraulic system, electrical system, an output device, pressure and displacement recorder five parts composition and for each wheel configuration different installed (see Fig. 1). 
Structure Characteristics. Master cylinder: the internal bushed steel cylinder, ensure the strength reliability of; using the combination of $\mathrm{V}$ and $\mathrm{Y}$ type sealing form, ensure the close connections; designs the piston guiding device, ensure the smooth operation of the piston.[5]

Mobile car: mainly by the small car body, the top of the cylinder, shaft bearings, shaft clamping mechanism, trolley guide rail, and other parts of the composition. Pushing oil cylinder for wheel lifting, in the upper part of the oil cylinder installed with a thrust bearing, so as to realize the whole wheels rotating U-turn; axle support has three types, respectively for the different supporting wheel, due to full suspension wheel weight greatly, and about serious eccentric structure, to support the car produce larger overturning moment, in order to solve this problem, especially in this kind of axle bearing designed and installed a set of wheel clamping mechanism, at the same time in the vehicle overturn are also to be taken into account, the use of a small wheel fixed channel steel rails, outer edge of the channel utilization, the car moves up and down effectively restrictions.

The car design with compact structure, simple operation, safe and reliable work, small size, can simultaneously realize the wheel up and down, left and right rotation turnaround of multiple operation, convenient and quick. [6]

Electrical control system: its outstanding characteristic is the use of pressure and displacement recorder, in the normal operation of the equipment. It can automatically record between equipment of working pressure and cylinder piston stroke, is that the relation of force and displacement, and print output, as the wheels "repair provides sufficient data, to satisfy the requirements of the maintenance rules.

Hydraulic system; using the variable displacement pump, it can realize the automatic regulation of low pressure and large flow, high pressure and small flow. In order to meet the requirement of back pressure test, the programmable pressure controller is selected.

\section{Design Calculation of Main Parameters}

Oil Pump and Motor Parameters. 1) automatically adjust the variable pump model: $10 \mathrm{PCY} 14-1 \mathrm{~B}$; displacement $\mathrm{Q}=10 \mathrm{ml} / \mathrm{r}$; Rated pressure $\mathrm{P}_{\max } 31.5 \mathrm{MPa} ;[7]$

2) $\mathrm{Y}$ series three phase asynchronous motor model: $\mathrm{Y} 132-4$, power $\mathrm{W}=7.5 \mathrm{~kW}$, speed $\mathrm{n}=1500 \mathrm{r} / \mathrm{min}$

Parameters of Main Oil Cylinder. 1)Cylinder diameter D

As the maximum pressure in the work $\mathrm{F}_{\text {max }}=300 \mathrm{t}$, and the piston adopts the structure form with the guide rod, the guide rod diameter $\mathrm{d}_{2}=160 \mathrm{~mm}$, preliminary estimate of cylinder diameter:

$$
\mathrm{D}^{2}=(4 \mathrm{~F} / \pi \mathrm{P})+\mathrm{d}_{2}^{2}=4 \times 300 \times 10^{4} / 3.14 \times 31.5 \times 10^{6}+0.16^{2}(\mathrm{~m})
$$

According to the standard set of cylinder diameter $\mathrm{D}=400 \mathrm{~mm}$

2) Maximum cylinder pressure

$$
\mathrm{F}_{\max }=\pi\left(\mathrm{D}_{1}^{2}-\mathrm{d}_{2}^{2}\right) \mathrm{P}_{\max } / 4=3.32 \times 10^{6} \mathrm{~N}=332 \mathrm{t}
$$

3) Strength check calculation of piston rod diameter $d_{1}$

$$
\mathrm{d}_{1} \geq 3.57 \times 10^{-2} \sqrt{\mathrm{F}_{\max } /[\sigma]}=141.9 \mathrm{~mm}([\sigma]=210 \mathrm{MPa})
$$

According to the piston rod diameter of the standard series $\mathrm{d}_{1}=160 \mathrm{~mm}$

4) Working stroke $S$ : According to the maintenance process, take $S=450 \mathrm{~mm}$.

Axle Diameter and Strength Check of Mobile Car. Wheel weight $\mathrm{G}_{1}=3.5 \mathrm{t}$; trolley for two axle four wheel structure, tread $\mathrm{L}=1000 \mathrm{~mm}$; car weight $\mathrm{G}_{2}=1 \mathrm{t}$; [8]Material selection of car axle 45 steel after quenching and tempering treatment; mechanical properties of 
materials $\sigma_{\mathrm{s}}=360 \mathrm{MPa}, \sigma_{\mathrm{b}}=650 \mathrm{MPa}$. The force analysis of the trolley wheel axle is shown in Fig. 3. [9]

Axial load:

$$
P=\left(G_{1}+G_{2}\right) k_{d}=5.4 t
$$

$\left(\mathrm{k}_{\mathrm{d}}\right.$ for dynamic load factor,because the car belongs to sudden load at work, so take $\mathrm{k}_{\mathrm{d}}=1.2$ )

Load per axle: $\mathrm{P}^{\prime}=\mathrm{P} / 2=2.7 \mathrm{t}$;

Support reaction force: $\mathrm{Y}_{\mathrm{A}}=\mathrm{Y}_{\mathrm{B}}=\mathrm{P}^{\prime} / 2$;

Bending moment:

$$
\begin{aligned}
& \mathrm{M}_{\text {max }}=\mathrm{Y}_{\mathrm{A}} \cdot \mathrm{L} / 2=\frac{9.8}{4} \mathrm{P}^{\prime} \mathrm{L}=6.6(\mathrm{KN} \bullet \mathrm{m}) \\
& \sigma_{\text {max }}=\frac{\mathrm{M}_{\text {max }}}{\mathrm{W}_{\mathrm{Z}}} \leq[\sigma]=\frac{\sigma_{\mathrm{S}}}{\mathrm{n}}=200
\end{aligned}
$$

( $\mathrm{n}$ for safety factor, take $\mathrm{n}=1.8 ; \mathrm{W}_{\mathrm{z}}$ for bending section coefficient, for circular cross sections, $\left.\mathrm{W}_{\mathrm{z}}=\pi \mathrm{d}^{3} / 32\right)$

So: $\mathrm{d} \geq \sqrt[3]{32 \mathrm{M}_{\max } / \pi[\sigma] \times 10^{2}=69.5 \mathrm{~mm}}$

Minimum axis diameter $\mathrm{d}=70 \mathrm{~mm}$ meet the strength requirements. [10]

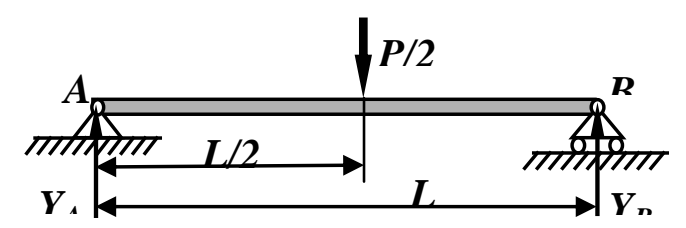

Figure 3. Force analysis of car axle

\section{Conclusion}

New wheel machine of pocketing wheelset detection is used in a device can be the back wheel and the back pressure test two process steps, simple operation, high maintenance efficiency, to axle no harm, safe and reliable and applicable to a variety of wheelset repair, with the traditional means of maintenance, superior.

\section{Reference}

[1] H. Xu: Mechanical Design Handbook (Mechanical Industry Press, China, 2001).(In Chinese)

[2] Y.Q. Nie and G.W. Meng: Mechanics of Materials (Mechanical Industry Press, China, 2009). (In Chinese)

[3] J.W. Wang: Hydraulic Transmission (Mechanical Industry Press, China, 2007). (In Chinese)

[4] X.K.Jin: Mechanical Engineering Mechanics (Higher Education Press, China, 2001). (In Chinese)

[5] X.Wang: Journal of Railway Engineering Society, (2008) No.4, p.91. (In Chinese)

[6] F.Y.Huang, Y.M.Mo, Y.Li and L.H.Wu: Railway Vehicles, Vol.43 (2005) No.6, p.33. (In Chinese)

[7] Y.M.Zhang and H.Yin: Railway Vehicles, Vol.46 (2008) No.9, p.39. (In Chinese) 
[8] F.Q.Li, Y.G.Zhao and P.F.Guo: Locomotive \& Rolling Stock Technology, (2015) No.4, P.38. (In Chinese)

[9] J.P.Feng and J.B.Zhang: Sci/Tech Information Development \& Economy, Vol.18 (2008) No.8, p.210. (In Chinese)

[10] Y.Li, Y.Wang, P.Wang, P.Li, K.M.Wang and J.Wang: Technology and Market, Vol.21 (2014) No.7, p.1. (In Chinese) 